\title{
The Comparative Study of Literary vs. Non- literary Text and Iranian EFL Learners' Performance on Cloze Tests of Inference
}

\author{
Reza Mokhtari \\ Department of Language Teaching, Science and Research Branch, Islamic Azad University, Kermanshah, Iran
}

\begin{abstract}
The present study aimed to explore whether there is any difference between the performance of EFL learners who read literary texts and those who read non-literary texts on inference demanding tests. Through convenience method of sampling, 30 Iranian senior university students of English translation B.A., studying at Islamic Azad University, Karaj Branch, Iran, who were of both male and female genders, ranging from 19 to 30 years of age took part in the current investigation. Once their language proficiency was measured by means of Oxford Placement Test, participants took part in an inference demanding test constructed by the researcher consisting of two cloze tests - one non-literary text and one literary text. The results from the t-test indicated that literary text had a more positive impact on the EFL learners' inferring ability than non-literary text. This study is particularly important given the fact that most reading materials are far from being shallow and require deeper interpretation. The major implication of the study was that incorporation of literature in general and literary texts in particular, in EFL curriculum, would serve many benefits specifically in the realm of comprehension and inference.
\end{abstract}

Index Terms - EFL, reading comprehension, literature, inference

\section{INTRODUCTION}

Reading plays a major role in EFL language use. Since it is a primary means of second and foreign language acquisition, its development as a skill should assume critical significance in pedagogy. Selection of EFL reading materials is equally important. Teachers have gone out of their way to utilise the prescribed reading materials which examine language learners' understanding of immediate components of reading passage, including structure, cohesion, and some other direct parts. As a result, the learners' vocabulary flourishes while their creativity and sense of inference remain untouched. It, therefore, can be argued that such objectives are hardly achieved in current reading materials prescribed by school authorities since they add little, if any, to their inferential ability, creativity, and imagination. Besides, they are by no means pleasure giving.

What EFL teachers should bear in mind is that any given text contains both explicit and implicit information. The latter is sometimes the cause of misunderstanding for many readers since the writer assumes the reader will infer the intended meaning from the text. Davoudi (2005) has put it this way: "As they construct their own models of meaning for a given text, readers and listeners alike use inference making extensively to fill in details omitted in text and to elaborate what they read" (p. 106). As a result, full understanding of a passage is not attainable simply by knowing all the words in the text and the reader must possess a sense of implication and inference to read fluently and reach to the very intention of the writer.

To build the desired interest in learners and detach them from being simply passive receivers, one way would be introducing the kind of books and texts that awaken their desire to be a part of it. Brown (2000) best captured the scene holding that "love" of reading plays a major role in propelling learners in acquiring reading skills successfully. This can in turn escalate their sense of inference, imagination, and creativity and the highlight of such materials is literary text.

In this line of defence, many authors and researchers have reckoned the appropriateness of integrating literature in EFL/ESL teaching (Bagherkazemi \& Alemi, 2010; Bhuvanesvari \& Jacob, 2011; Carter, 1997; Duff \& Maley, 2003; Gajdusek, 1988; Khatib, Rezaei, \& Derakhshan, 2011; Lazar, 1994;; McKay, 1982; Savvidou, 2004). The current study, thus, was based on this assumption that not only is literature a source of individual pleasure, but also a resourceful language learning that helps EFL learners infer concealed ideas between the lines. It, therefore, sought to find out whether there was any difference between the performance of EFL learners who read literary text and those who read non-literary text on inference demanding tests.

\section{REVIEW OF RELATED LITERATURE}

\section{A. Literature}

Since the acknowledgment of literature as a key constituent to EFL classroom as reading material, arguments for and against its incorporation were put forth as it was not popular with all scholars throughout the century. A close review of 
the vindications suggested by proponents and opponents of incorporating literature in EFL classrooms will illuminate the fact that consensus and controversy over the issue ground on almost the same rationales.

\section{Arguments against Integrating Literature in TEFL/TESL.}

Any given argument or notion is not without its opponents; one such notion is the idea of integrating literature in language teaching. McKay (1982) mentioned three general reasons why literature does not guarantee language learning: First, structural complexity of literature and its unique use of language is no help to acquiring of grammar. This is also a matter of concern as Savvidou (2004) has noted "the creative use of language in poetry and prose often deviates from the conventions and rules which govern standard, non-literary discourse" (p. 2). Second, students with academic or occupational goals cannot benefit from studying literature. And since literature is representative of a particular culture, its comprehension is rather difficult.

Along with the aforementioned oppositions, there are a number of hardships with literature which undermine its uses in EFL/ESL classroom. A series of them have been enumerated by Lazar (1994). He believed that in the first place language grading is a noteworthy matter since "many literary texts, whether prose or poetry, are written in language which includes vocabulary, grammatical structures, and syntax considered too complicated to be included in the syllabus for learners at lower levels" (p. 115). This is well supported by Savvidou (2004) when she specified the discourse of literary texts compared to those of non-literary. In her assumption, literary discourse requires the learner to "infer, anticipate and negotiate meaning from within the text to a degree that is not required in non-literary discourse" (p. 2). The second objection according to her is the literary competence of students at lower grades which consequently raises the question whether they have been successful at making a correct interpretation of a literary text. As for the third opposition, Lazar (1994) claimed "A further problem with using literature at lower levels is that it is considered too highly specialized an activity to be of interest to less advanced students" (p. 116). This was further supported by Akyel and Yalcin (1990, as cited in Su, 2010) whose findings suggest that literary texts are interesting to advanced student while lower level students in terms of proficiency think it is unattractive and boring.

\section{Arguments for Integrating Literature in TEFL/TESL.}

Justifications for the incorporation of using literary texts in EFL/ESL classrooms are numerous and the great number of authors, researchers, and teachers who have written and applied literature in defense of it tells its own tale. The grounds for such decision are almost common among many: Literature is interesting, cultural driven, authentic, and a good source of linguistic knowledge.

One common ground for the utilization of literature is the interest learners take in reading literary texts. McKay (1982) reported "to the extent that the students enjoy reading literature, it may increase their motivation to interact with a text and thus, ultimately increase their reading proficiency" (p. 531). In that sense, reading proficiency is in close relationship with motivation which is in turn the result of the interest one takes in reading. Motivation is undisputedly a driving force to fulfill any action and reading proficiency is no exception. In this regard, Bagherkazemi and Alemi (2010) have noted out that "in order to interact with, rather than react to a text, reader motivation is of critical significance and literature, when approached in the right way, does guarantee this motivating effect" (p. 6). In addition, literary texts enjoy characters which readers easily identify with and so saying they share emotions and feelings which finally lead to personal involvement (Adlert, 1972, as cited in Thom, 2008; Floris, 2004, as cited in Khatib \& Nourzadeh, 2011).

One obvious benefit literary style can serve is involvement and joy which facilitate learning by fostering more active and critical thinking which in turn results in an opportunity for learner-centered activities and collaborative group work (Gajdusek, 1988). When it comes to story as a perfect literary medium to teach language, personal involvement and critical thinking are major components as Carter (1997) assumed. He has argued:

A heightened degree of attentiveness to the story can be brought about by prediction. There is increased involvement as a result of the natural desire of seeing one's own expectations fulfilled or contravened... In the face of 'gaps' in the narrative, ... prediction serves the function of allowing that gap to be filled by the reader. (p. 173)

Amer (2003), in defence of using authentic stories in language teaching syllabus reckoned the motivating impact of such materials on thinking skills of language learners. Similarly, since motivational benefits lie within stories, Erkaya (2005) has looked at it as a great help to acquire the four language skills - listening, speaking, reading, and writing.

So far, it can be inferred that in spite of the difficulties the practitioner can encounter, using literature is appealing to students. It gets the students drawn in trying to figure out what the text is about. It eases the expression of emotions, as literary works depict human emotions and perceptions. Therefore, his sense of accomplishment is greatly felt by himself once he draws to a close with the activity. And finally, it broadens the sense of language as more than just for monotonous practice and drill.

An alternative justification of using literary text in EFL/ESL classroom is the abundance of cultural information existing in the heart of literature (Su, 2010; Thom, 2008; Van, 2009, as cited in Bagherkazemi \& Alemi, 2010). Many scholars regard this as a drawback since, they argue, a different culture from that of the language learners' own will end in confusion among them. However, the number of proponents is far more than the opponents when it comes to culture and its impact. The themes used in literature are common to all cultures and this is the treatment of the themes which is different across the cultures (Duff \& Maley, 2003). It can be inferred that common to all languages there is a certain list of themes including, love, hate, death, nature, etc. which are dealt with differently from culture to culture. 
Savvidou (2004) in her defence of the necessities in teaching culture through language reckoned communicative competence as a major reason. From her perspective, in order for one to gain communicative competence, mastery of structure and form does not seem to be sufficient since comprehending the intended discourse requires social and cultural contexts, and this can be easily achieved by means of incorporating literature in EFL teaching. Erkaya (2005) named this potential as higher-order thinking skills. She went on to claim that critical thinking is bare bone essential in interpreting texts and this advantage is most held by intermediate and advanced language learners. The justification of communicative competence and critical thinking was also utilised by Bhuvaneswari and Jacob (2011) who asserted:

A student can learn and use words effectively in different contexts through literary texts. Students also become more prolific and exploratory (critical evaluation) when they begin to identify the copiousness of the language they are trying to learn so as to make use of some of them with efficacy. This really improves their communicative competence. (p. 157)

Another common ground among many EFL/ESL scholars, teachers and researchers in defense of merging literature with language teaching and learning process is the concept of authenticity. In his definition of authenticity, Berardo (2006) cited Wallace (1992, p. 145) as "real-life texts, not written for pedagogic purposes." Such text is not written to emphasize its form, but content. This transference of new information was equally emphasized by Berardo (2006) since it is highly motivating. Advantages of using authentic materials in language teaching are numerous. Berardo (2006) has listed them as:

1- Having a positive effect on student motivation

2- Giving authentic cultural information

3- Exposing students to real language

4- Relating more closely to students' needs

5- Supporting a more creative approach to teaching

Many text types enjoy such feature including travel timetables, city plans, forms, pamphlets, cartoons, advertisements, newspaper, magazine articles, and literature. This can provide appropriate reading material which can in turn serve different purposes. There are four types of authenticity which is used in language classrooms:

1- Authenticity of the texts which we may use as input data for our students

2- Authenticity of the learners' own interpretations of such texts

3- Authenticity of tasks conducive to language learning

4- Authenticity of the actual social situation of the classroom language (Breen, 1985, as cited in Berardo, 2006)

Bagherkazemi and Alemi (2010) cited Van (2009) as claiming that authenticity provides the ground for meaningful context to enhance the interpreting and inference ability in EFL learners. This is obviously in line with the principles of CLT which presses the role of authentic materials in language learning. Khatib et al. (2011), too, have identified literary texts, particularly novels and dramas, as two authentic materials which can help EFL/ESL learners in their developing of target language.

The benefits of literary texts in EFL classroom are multi-faceted and an obvious impact is on language learners' expansion of linguistic abilities. This was well supported by McKay (1982, p. 531) when she asserted "literature can be useful in developing linguistic knowledge both on a usage and use level." McKay is not alone there though. Thom (2008) equally has argued that literary text can give EFL learners ample opportunities "to use and develop such sub skills as deduction of meaning from linguistic and situational context, relating text to knowledge and experience of the world, responding to text, creative writing, etc." (p. 122).

The controversy of language usage and use was also discussed by Savvidou (2004) who regarded literature as a perfect means to instruct grammatical structures, word forms and common expressions, "Much more, however, can be gained by exploring the way such atomistic aspects of language are used in discourse, i.e. at a suprasentential level." In this respect, however, Gajdusek had a different idea (1988); he considered literature as decontextualized, but it is never looked at as a shortcoming since it enjoys two features which make literature a great ground for TEFL settings. In the first place literary texts have "internal coherence" which makes interpretation of them rather simpler. In the second place, literature enjoys "conscious patterning" which means the pattern of any given literary text is an attempt to connect intellectual, emotional and physical experiences.

Two most cited justifications of using literature are the positive effect it has on one's vocabulary and grammatical knowledge (Gajdusek, 1988; Khatib et al., 2011; Povey, 1967; Su, 2010; Van, 2009, as cited in Bagherkazemi \& Alemi, 2010). There is also a consensus that literature consolidates all four skills: listening, speaking, reading, and writing. Povey (1967) and Erkaya (2005) have asserted that literature, with its extensive and connotative vocabulary and its complex syntax, can expand all language skills. Khatib et al. (2011), too, have advocated the main ideas claiming that literature provides a resourceful ground to practice all major language learning skills:

Having the learners complete a poem or short story in cloze form is very encouraging .... For speaking purposes, the events in a poem, novel, or short story can be associated with the learners' own experience in real life.... For listening purposes, ... it is good for practicing reading subskills including skimming, scanning, and finding the main ideas. Reading in literature is a combination of reading for enjoyment and reading for information. Therefore, it bridges the lacks in non-literary texts. (p. 203)

B. Inference: Definition and Indication 
Comprehending a text involves more than knowing the correct pronunciation of the words, identifying their meanings, and being able to find information explicitly stated (Cain, Oakhill, Barnes, \& Bryant, 2001; Yeh, Mctigue, \& Joshi, 2012). There are many strategies to reading comprehension such as inferring, generalizing, making connections, visualizing, synthesizing, predicting, summarizing, using context clues, drawing conclusions, monitoring, asking questions, and finding main ideas and all should be applied to be able to understand a text. One determining factor which leads to this realization is inference making (Collins, Brown, \& Larkin, 1977; Davoudi, 2005; Kispal, 2008; Kopitski, 2007; Thornbury, 2005; Yeh et al., 2012). Kispal (2008) believed that "Inference can be as simple as associating the pronoun 'he' with a previously mentioned male person. Or, it can be as complex as understanding a subtle implicit message, conveyed through the choice of particular vocabulary by the writer and drawing on the reader's own background knowledge" (p. 2).

First and foremost, an operational definition seems critical. Although different researchers have put forth divergent definitions, it should be noted that all the definitions are similar in core: The inference is not explicitly stated; it is implied by the writer. "An inference is the ability to connect what is in the text with what is in the mind to create an educated guess" (Beers, 2003, as cited in Kopitski, 2007). In an attempt to define inference, Kispal (2008) held "The ability to make inferences is, in simple terms, the ability to use two or more pieces of information from a text in order to arrive at a third piece of information that is implicit" (p. 2). A comparison of the two definitions sheds light on the fact that the latter definition ignores the major role of mind which was captured by Beers (2003). A more comprehensive description of inference has been made by Pennell (2002) as "Inferential comprehension is often described simply as the ability to read between the lines. It requires a reader to blend the literal content of a selection with prior knowledge, intuition, and imagination for conjecture or to make hypotheses" (p. 1). His definition has elaborated on the 'mind' stated earlier. He adds intuition and imagination as constituents of 'mind'.

An inference is, then, a meaning that is implied rather than directly stated. Inferences are suggested through clues that lead the reader to predict and draw conclusions. For instance, instead of making a direct statement, these people are wealthy, an author could suggest that concept by describing an elaborate house, expensive properties, and prominent friends. Fiction and poetry writers in particular, are aware of more details than they disclose in the texts they compose. This requires inferences such as drawing conclusions, making predictions, and connections to other texts and experiences possible for their readers. Understanding an inference is what is intended as reading between the lines, as the suggestion, rather than the actual words, carries the meaning. Kopitski (2007) has regarded this type of reading as acting out much like a "detective" in search of a clue. This creates an urge on the side of reader to expand on inference ability without which comprehension seems lame.

\section{Types of Inferences.}

In an attempt to distinguish different kinds of inference, an extensive list was discovered as each researcher has looked at it from a different dimension. Cain et al. (2001), for instance, have differentiated between coherence and elaborative inferences. The former is essential for adequate comprehension of text while the latter enhances the text representation but is not critical in understanding it. "Generation of a coherence inference required integration of different pieces of information from within the text, whereas generation of an elaborative inference required the reader to integrate information from the text with prior or general knowledge" (ibid, p. 851). In a different study, Kopitski (2007) recognized the importance of inference in reading comprehension and categorizes it differently:

1 - Recognize the antecedents for pronouns

2- Figure out the meaning of unknown words from context clues

3- Figure out the grammatical function of an unknown word

4- Understand intonation of characters' words

5- Identify characters' beliefs, personalities, and motivations

6- Understand characters' relationships to one another

7- Provide details about the setting

8- Provide explanations for events or ideas that are presented in the text

9- Offer details for events or their own explanations of the events presented in the text

10- Understand the author's view of the world

11- Recognize the author's biases

12- Relate what is happening in the text to their own knowledge of the world

13- Offer conclusions from facts presented in the text

Inference is further classified into two types, text-based and model-based. The former fills in the missing links between the surface structure with a special look at context, and knowledge about the world. This emphasises the idea that the inference process looks for meaningful associations between different suggestions in the text. Model-based view, however, holds that the purpose of inference is to make a basic model, which organises and adds to the surface structure in the text. In this view, inference is monitored by a target structure that indicates the a priori restraints on the kind of model to be created. Such target structure acts as an organizational code to steer inference procedures (Collins et al., 1977).

\section{Factors Affecting Inference Making.}


Several factors which might have an effect on inferring ability have been proposed in the related literature and the most frequent ones collectively accepted are: background knowledge, goal, and interest.

Each EFL classroom is one of a type and students come with different personal experiences. These personal experiences as well as cultural varieties can touch a reader's ability to infer in reading a text and this has attained widespread acceptance (Davoudi, 2005; Kispal, 2008; Kopitski, 2007; Phillips, 1989; Thornbury, 2005). Readers' background knowledge is bare bone essential in the comprehension of text via inference as it accelerates comprehension and unburdens working memory to link new information and already possessed knowledge to infer (Davoudi, 2005). Authors use inferences which require connecting old information to what is being read at the time. Clues that imply meaning may draw on a supposed knowledge of history, current issues, or social concerns. Just as in making the connection to figure out the punch line of a joke, the reader must make a connection in order to infer the implications.

Phillips (1989) recognised the role of background knowledge and enumerated three reasons why this dependence is important: First, an interaction of textual information and background knowledge is required since neither of them alone is enough to draw inferences. Second, background knowledge allows the making of alternative hypotheses in inferring. Third, with absence of background knowledge one is not able to assess the strength of inferences to generalizations and rationalizations, thereby making background knowledge an integral part of inferential reasoning.

The controversy over whether language proficiency in general and reading proficiency in particular have any impact on the number of inferences made by readers is ongoing. Kispal (2008) believed that inference ability is in close connection with readers' vocabulary knowledge. Davoudi (2005) held that competent readers can link between ideas in the text, as well as the text and their prior knowledge, to build a consistent representation of the text. Although studies have shown that less skilled readers perform poorly on texts that require inference (Graesser et al., 1992; Kispal, 2008; Pennell, 2002), it is difficult to find out whether their poor performance is the result of deficits in inferential capacity or failure to encode an accurate representation of the text.

However, Pennell (2002) is not in line with the aforementioned hypothesis. "Proficient readers are better able to remember and apply what they have read, create new background knowledge for themselves, discriminate and critically analyse text and authors, and engage in conversation and/or other analytical responses to what they read" (ibid, p. 2). Readers use both stated and unstated ideas to draw logical conclusions. They use the facts, the hints, and their prior knowledge to piece together meaning. The facts and clues lead to assumptions, which then lead to conclusions. Thus, poor readers might not extract enough evidence and clues from the text which in turn can lead to weaker inferences.

A possible route through which inference ability is influenced is the one with affective variables, such as interest, and goal. Reader's purpose might pave the way to make inferences online and they are more likely to be drawn if they address familiar topics. While the vast majority of previous studies on text processing have focused on the structural importance of the text, the affective variables have been ignored for several decades (Davoudi, 2005). Kintsch (1980) has suggested a comprehensive explanation of interest. He distinguished two types of text-based interest, emotional interest and cognitive interest. Emotional interest is aroused by occurrences with sentimental functions, such as death, sex, etc. Cognitive interest, on the other hand, is created when information in the text are related to the reader's prior knowledge and is determined by three factors: First, how much prior knowledge a reader has on the topic; second, the extent of doubt (unexpectedness or surprise) about the information; and finally, "postdictability" of the information, connoting how well the information can be meaningfully associated with other parts of the text. Cognitive interest, in that sense, is considered to be an inverted U-shaped function of the knowledge and uncertainty. That is, if a situation is very familiar or very unfamiliar, or if a state of affairs are easily expected or not expected at all, the interestingness declines (as cited in Davoudi, 2005).

\section{MEthodology}

\section{A. Participants}

The sample in this study consisted of 30 Iranian senior university students of English translation B.A., studying at Islamic Azad University, Karaj Branch, Iran. They were of both male and female genders, ranging from 19 to 30 years of age. The convenience method of sampling was used in this study. All participants had passed a nationwide university entrance exam to be eligible for admitting in the aforementioned university and had attended reading comprehension courses during the past 6 semesters. The sample was true representative of the entire population given that they were all majoring at an English language major. Oxford Placement Test (OPT) was administered to homogenize the attendants based on their general language proficiency. Participants whose scores on OPT were beyond the range of \pm 2 standard deviation from the mean (56.77) were set to be discarded; however, Kolmogorov-Smirnov test indicated a normal distribution of scores.

\section{B. Instrumentation}

The study aimed at investigating the possible relationship between literary and non-literary text types and the EFL learners' performance on inference demanding tests. The researcher's assumption was the presence of a difference in the EFL learners' reading comprehension of these two text types. Accordingly, two tests contents were developed and administered in the present study. 
A validated test of language proficiency (Oxford Placement Test), retrieved from www.oup.com, was administered as a means of homogenizing the participants in terms of their language proficiency. The test consists of 60 multiple-choice items. An analytic look at the test suggests that language components tested were grammar, vocabulary, as well as English reading comprehension. The allotted time for all 60 items was 30 minutes with 5 extra minutes to transfer the answers to the answer sheets. An answer sheet was devised to ease the process of correction.

A cloze test including 47 multiple-choice items was constructed by the researcher. The test consisted of a non-literary text with 24 items and a literary text (poetry) with 23 items. Two texts were stapled together as the booklet form. In order to determine whether the items that appeared in the inference test were of proper functioning quality, it was vital for the cloze tests to be piloted and revised. The total test can be found in appendix A.

The purpose of this process was to screen the dis-functioning items so that the most suitable distracters would be included in the final version of the cloze test. The researcher included six alternatives in each item. After the pilot administration, the items were thoroughly analysed. After item analysis, those four alternatives that had the best discrimination index values were selected for every 47 items and the residue was discarded.

The non-literary passage entitled as "why the Yogic way for food?" was chosen from the book Essential Reading for IELTS (Gordon \& Harding, 2007) with a readability of 19.80. The poetry is chosen from one of the collections of Maya Angelou under the name Phenomenal Woman (1978).

Poetry is a type of text where imagination and figurative language dominates which in turn undermines the validity of readability formulas. Therefore, it was decided that the best way to control the poem's difficulty and readability would be to ask 15 EFL teachers for their reflection on the text difficulty. Twelve out of 15 felt the two texts were almost of the same difficulty. It was further supported with piloting the test on 10 upper-intermediate EFL language learners who were studying Summit 1A from Top Notch series. Four of the test takers claimed that the poem was more difficult than the prose.

Through test piloting, a sufficient test time was determined ( 35 minutes). The reason why poetry is chosen among a long list of literary genres and styles is the fact that poetry is symbol of literariness in literature which could best carry the aims of the present study. The questions for both texts were devised in a way that their alternatives directly tested the test takers' inference making ability.

Participants' inference making ability was tested against these misleading factors; some of which might have triggered them to choose the correct response which was considered as one of the research imposed limitations. Participants' ability to guess, infer and retrieve the original response was desired.

\section{Data Analysis}

The tests administered among all participants were scored by the researcher. In the placement and inference tests, every true response to each item was awarded 1 point; while, for each item that was unmarked or marked erroneously, zero score was assigned. Since the number of questions varied among the test and that the researcher intended to come to a correlation between them, percentage of each score would act as a true indicator of values. Different statistical procedures were performed for the analysis of the scores. Measures of central tendency including mean scores and standard deviations of the placement and inference tests were tabulated.

The data were undertaken test of normality to decide on the parametric/nonparametric tests. To study the difference between the performance of the participants on literary and non-literary tests, paired-samples t-test was conducted. As it was clarified earlier, an Oxford Placement Test (OPT) was administered in order to determine the participants' language proficiency level $(n=30)$. Fig. 1 shows the frequency of the scores obtained in the test.

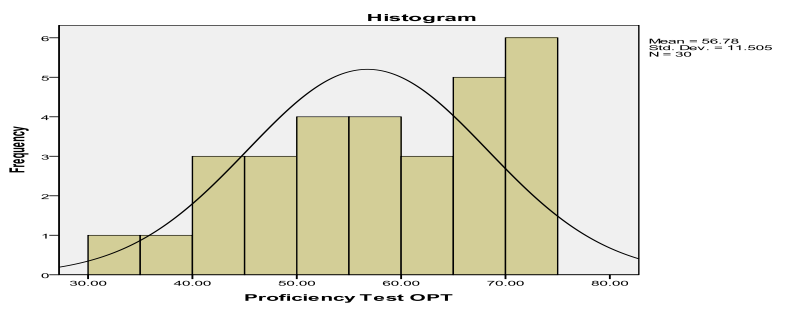

Figure 1. Distribution of participants in Oxford Placement Test (OPT).

It can be seen from the Fig. 1 that scores of two test takers were below 40 and accumulation of scores is between 40 and 70 which consist of over 73 per cent of total scores obtained. Accordingly, 20 percent of participants had a score over 70. As Table 1 shows, minimum and maximum scores obtained in the OPT were 30 and 73 respectively which suggests a range of almost 43, and a mean of 56.77. The variance for all the scores obtained equals 132.36 with a standard deviation of 11.50 from the mean.

TABLE I.

STATISTICAL DESCRIPTIVE DATA OF THE PARTICIPANTS IN OXFORD PLACEMENT TEST

\begin{tabular}{|l|l|l|l|l|l|l|l|l|l|}
\hline Test & $\mathrm{N}$ & Range & Min. & Max. & Mean & Median & Mode & Variance & Std. Deviation \\
\hline Oxford Placement Test & 30 & 43.33 & 30 & 73.33 & 56.7753 & 58.33 & 50 & 132.364 & 11.50494 \\
\hline
\end{tabular}


Based on the obtained results from Table 2, consistency of items in OPT was measured through reliability formula (K-R 21=0.99). And the Kolmogorov-Smirnov Test approves the distribution function of the results as normal. The result of the performed test appears in the Table 3.

TABLE II.

RELIABILITY OF OXFORD PLACEMENT TEST

\begin{tabular}{|l|l|l|}
\hline Number of Students & Number of Items & K-R 21 Method \\
\hline 30 & 60 & 0.9934 \\
\hline
\end{tabular}

TABLE III.

ONE-SAMPLE KOLMOGOROV-SMIRNOV TEST FOR OXFORD PLACEMENT TEST
\begin{tabular}{|l|l|l|}
\hline $\mathrm{N}$ & Mean & 30 \\
\hline \multirow{2}{*}{ Normal Parameters ${ }^{\mathrm{a}, \mathrm{b}}$} & Std. Deviation & 56.7753 \\
\hline Kolmogorov-Smirnov Z & 11.50494 \\
\hline Asymp. Sig. (2-tailed) & 708 \\
\hline
\end{tabular}

a. Test distribution is Normal.

b. Calculated from data.

The following boxplot in Fig. 2 visualises the degree of dispersion and skewness in the data, and identifies outliers. It also eases the study of the distributional characteristics of scores in OPT.

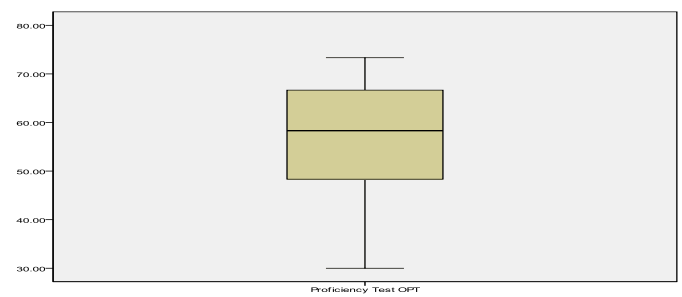

Figure 2. Boxplot for OPT.

According to Fig. 2, range of scores in OPT is relatively wide and the lower whisker is a tall one suggesting that $25 \%$ of scores below the lower quartile are dispersed across a wider range compared to upper whisker. The box, however, has a median right in the midpoint of quartile 2 and 3 to show a symmetric dispersion with a small skewedness. It can also be seen from the figure that there is no outlier in the score which implies that all scores lie within the lowest and highest value. This, in turn, suggests that distribution of the population from which sample was taken is normal. An analytic look at the following figures indicates that distributions of the two tests are bell shaped, thus normal since many scores accumulated in the center.

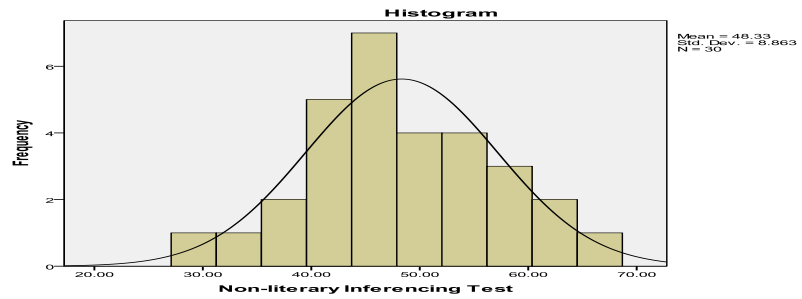

Figure 3. Distribution of participants in non-literary inference test.

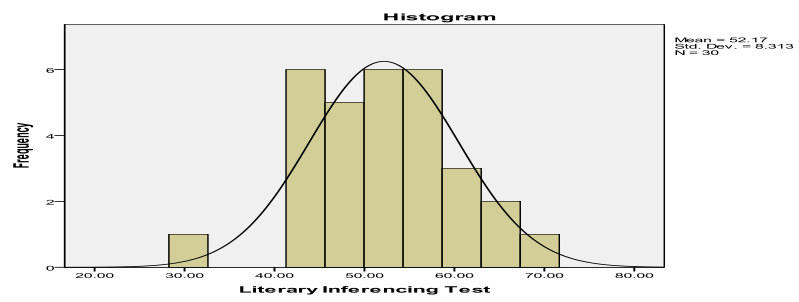

Figure 4. Distribution of participants in literary inference test

The following figure depicts the degree of dispersion and skewness in the data, and identifies outliers in non-literary and literary inference tests. 


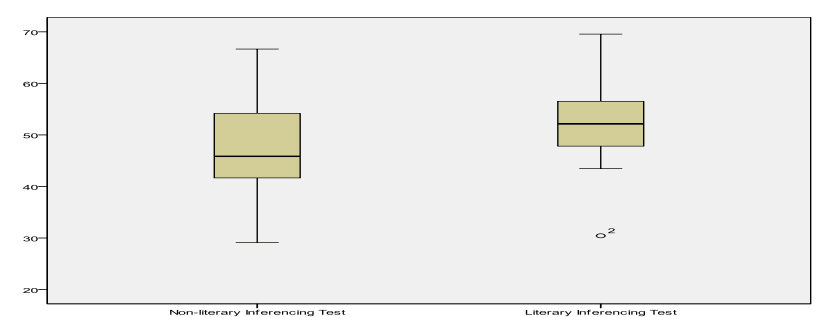

Figure 5. Boxplots for (non)literary inference tests.

An analytic look at Figure 5 implies that the height of non-literary inference test boxplot is normal, suggesting that distribution of scores is relatively consistent. Lower and upper whiskers are almost equal in size, but the second and third quartiles have different height and the median is closer to lower quartile. This shows that the top 50\% of scores have greater variety. It can also be seen from the figure that there is no outlier in the scores which implies that all scores lie within the lowest and highest value. This, in turn, suggests that distribution of the population from which sample was taken is normal.

The boxplot for literary inference test, however, is situated in the upper part of the scores range. The lower whisker is a short one suggesting that $25 \%$ of scores below the lower quartile are dispersed across a shorter range compared to upper whisker. The box, however, has a median right in the midpoint of quartile 2 and 3 to show a symmetric dispersion. It can also be seen from the figure that there is only one outlier in the score which implies that almost all scores lie within the lowest and highest value. This, in turn, suggests that distribution of the population from which sample was taken is normal.

The obtained mean scores of non-literary (NL) and literary (L) inference tests for total number of participants $(\mathrm{N}=30)$ were $(\mathrm{NL}=48.32, \mathrm{~L}=52.16)$ and a standard deviation of $(\mathrm{NL}=8.86, \mathrm{~L}=8.31)$. Non-literary inference test had a range of 37.50 while the range for literary inference test was 39.13 .

TABLE IV.

DESCRIPTIVE STATISTICS OF THE PARTICIPANTS IN (NON)LITERARY INFERENCE TESTS

\begin{tabular}{|l|l|l|l|l|l|l|l|l|l|}
\hline Test & $\mathrm{N}$ & Range & Min. & Max. & Mean & Median & Mode & Variance & Std. Deviation \\
\hline Non-literary Test & 30 & 37.50 & 29.16 & 66.66 & 48.3297 & 45.83 & 45.83 & 78.550 & 8.86282 \\
Literary Test & 30 & 39.13 & 30.43 & 69.56 & 52.1683 & 52.17 & $43.47^{\mathrm{a}}$ & 69.102 & 8.31276 \\
\hline
\end{tabular}

a. Multiple modes exist. The smallest value is shown

As the Table 5 demonstrates, the participants' responses to both tests were relatively consistent. The calculated Kolmogorov-Smirnov test in Table 5 implies the normal distribution of the two tests $(\mathrm{NL}=.791, \mathrm{~L}=.626)$ and the feasibility of the parametric paired-samples t-test.

TABLE V.

ONE-SAMPLE KOLMOGOROV-SMIRNOV TEST FOR NON-LITERARY INFERENCE TEST

\begin{tabular}{|c|c|c|}
\hline & Non-literary Inference Test & Literary Inference Test \\
\hline $\mathrm{N}$ & 30 & 30 \\
\hline \multirow{2}{*}{ Normal Parameters ${ }^{\mathrm{a}, \mathrm{b}}$} & 48.3297 & 52.1683 \\
\hline & 8.86282 & 8.31276 \\
\hline Kolmogorov-Smirnov Z & 791 & .626 \\
\hline Asymp. Sig. (2-tailed) & .559 & .828 \\
\hline
\end{tabular}

b. Calculated from data.

The researcher collected the quantifiable data from participants by means of non-literary and literary inference cloze tests. With regard to the nature of the present investigation which is mainly concentrated on comparing the mean scores of the two groups, the paired-samples t-test formula was used to describe the significance of the difference between the mean scores of the two tests which were administered to a single group of participants. Considering the 0.95 level of significance and $p$-value $<.05$, the decision making principle is as follows:

1 - If the significance of two-tailed t-test is less than or equal to $(0.05)$, the null hypothesis is rejected ( $p$-value $\leq .05)$.

2 - If the significance of two-tailed t-test is more than (0.05), the null hypothesis is confirmed ( $p$-value $>.05)$.

The hypothesis of this study states that: "There is no difference between the performance of EFL learners who read literary texts and those who read non-literary texts on inference demanding tests." To discuss this hypothesis, at first the mean, standard deviation, and standard error of the mean for both tests were computed which are shown in Table 6.

TABLE VI.

DESCRIPTIVE STATISTICS OF INFERENCE TESTS

\begin{tabular}{|l|l|l|l|l|l|}
\hline & Mean & Std. Deviation & Std. Error Mean \\
\hline Pair 1 & Non-literary Inference Test & 48.3297 & 30 & 8.86282 & 1.61812 \\
\hline & Literary Inference Test & 52.1683 & 30 & 8.31276 & 1.51770 \\
\hline
\end{tabular}


The participants' mean score of non-literary inference test was 48.32 with the standard deviation 8.86 and literary inference test's mean was 52.16, with the standard deviation 8.31. Although participants were similar in both groups, it can be inferred from the mean scores of the tests that they outperformed on the literary passage compared to nonliterary passage.

In order to compare the mean scores of participants in both tests paired-samples t-test was carried out. Based on the $\mathrm{t}$-test results in Table 7, differences between mean scores of the two tests was found to be significant $(\mathrm{t}(29)=-2.214$, $\mathrm{p}$ $<0.05$ ). Based on the given data, a difference existed between the performance of EFL learners who read literary texts from those who read non-literary texts on inference demanding tests. That is to say, since the mean score in literary inference test was greater than the mean score in non-literary inference test, it could be concluded that literary text had significantly a more positive impact on the learners' inference making ability than non-literary text, thus the results rejected the first null hypothesis.

TABLE VII.

PAIRED-SAMPLES T-TEST FOR (NON)LITERARY CLOZE TESTS

\begin{tabular}{|c|c|c|c|c|c|c|c|c|}
\hline & & \multicolumn{5}{|c|}{ Paired Differences } & & \multirow{3}{*}{ df Sig. (2-tailed) } \\
\hline & & \multirow[t]{2}{*}{ Mean } & \multirow[t]{2}{*}{ SD } & \multirow{2}{*}{$\begin{array}{l}\text { Std. Error } \\
\text { Mean }\end{array}$} & \multicolumn{2}{|c|}{$\begin{array}{l}95 \% \text { Confidence Interval of } \\
\text { the Difference }\end{array}$} & & \\
\hline & & & & & Lower & Upper & & \\
\hline Pair 1 & Non-literary \& Literary Inference Test & -3.83867 & 9.49548 & 1.73363 & -7.38434 & -.29300 & -2.214 & 29.035 \\
\hline
\end{tabular}

\section{Discussion}

\section{A. Conclusion}

The present study was set up to determine the impacts of literature on EFL learners' inference ability. As a finding in the present study, there was a significant difference between the performance of EFL learners who read literary texts and those who read non-literary texts on inference demanding tests. In other words, as the t-test results showed, participants had a better deal with inference demanding questions when they read literary text compared to non-literary one.

One explanation for this result is that literature has internal coherence and conscious patterning (Gajdusek, 1988). By internal coherence, a given sentence in a literary discourse is closely related to other sentences in the same literary work. This, in turn, "engages the reader in interpretation, meaning negotiation and the generation of coherent discourse-based meaning" (ibid). Conscious patterning, too, emphasises the recrudesce of many features such as sounds, meanings, and structures.

An additional consideration is that literature is widely accepted as authentic (Bagherkazemi \& Alemi, 2010; Berardo, 2006). Authenticity of language in literary texts causes the reader to be exposed with the kind of language in use in real world, thus perceiving and comprehending it with more ease and comfort.

In conclusion, it is unquestionable that literature is of great importance in EFL learning since the benefits it serves are numerous as it is a multi-dimensional means to create a safe ground for language learning and teaching.

\section{B. Implications}

The implications of this study can be discussed from applied perspectives. The results are useful in teaching foreign languages. They will enable the foreign language material developers to design the kind of texts that assist language learners in the process of learning. One critical missing element in the current EFL textbooks is literature. The present study outlined the many reasons why literature in general and literary texts in particular might prove helpful in the course of language learning; thus, their incorporation in EFL textbooks should be considered.

First and foremost, literature can be used with students of all proficiency levels. What should simply be done is considering the natural grading of literary works to fit different language proficiency levels. Another major justification for the use of literary texts as EFL material is the interest language learners take in such discourse. The cause of such interest is perhaps the life-like nature of literature. Novels, for instance, consist of characters that the reader might identify with. Identification with characters not only can trigger more interest in readers, but help comprehend the text better. One explanation for such phenomenon is a belief that literary texts call for negotiation and transaction; therefore, far from being a passive reader, one makes his/her own meaning.

Another reason why literature should be integrated into EFL materials is the importance of teaching EFL learners the target language culture where the language is used (Duff \& Maley, 2003). In short, social and cultural contexts help them comprehend the intended discourse. Improving linguistic knowledge is an alternative rationale for the use of literature. It is a perfect means to instruct grammatical structures, word forms and common expressions (Savvidou, 2004). Finally, literature is perfectly authentic. This should be noted that the way students learn a language becomes easier when they get to know how the language is used in real contexts.

The results from the present research shed light on how literary text can make readers delve into the deeper layers of the reading passages which is technically called inference. After all, comprehending reading passages is far more than knowing the meaning of the individual words. Inference making ability is a necessity of comprehension since many 
passage features can be approached through inference making. Likewise, this study demonstrated how EFL readers could perform better in their dealing with grammatical inferences when they read literary text. The vindication might be the natural predictability of the language in literature which triggers word recognition. In the spirit of natural language acquisition, literature is not grammatically sequenced. Therefore, it is suggested that teachers consider literature in teaching grammatical and lexical inferences in EFL classrooms.

\section{APPENDIX A. (NON)LITERARY INFERENCE TESTS}

INSTRUCTIONS: Choose the most appropriate answer. You will have $\mathbf{1 5}$

minutes.

\section{Phenomenal Woman by Maya Angelou}

Pretty women wonder where my secret lies.

I'm not cute or built to ....1...... fashion model's size

But when I ....2... to tell them,

They think I'm ....3... lies.

I say,

It's in the....4... of my arms

The span of my hips,

The stride of my step,

The curl ....5... my lips.

I'm a woman

Phenomenally.

...6.....woman,

That's me.

I walk into ...7 ... room

Just as cool as you please,

...8.... to a man,

The fellows stand or

...9.... down on their knees.

Then they swarm ....10... me,

A hive of honey bees.

I...11...,

It's the fire in my eyes,

$\ldots .12 \ldots$ the flash of my teeth,

The swing....13 .... my waist,

And the joy in my ....14.....

I'm a woman

Phenomenally.

Phenomenal woman,

...15....'s me.

Men themselves have wondered

What....16.... see in me.

They try so much

...17.... they can't touch

My inner mystery.

....18... I try to show them

They say ....19.... still can't see.

I say,

It...20... in the arch of my back,

The....21.... of my smile,

The ride of my ....22....,

The grace of my style.

I'm ....23.... woman

Phenomenally.

Phenomenal woman,

That's me.

$\begin{array}{ll}\mathbf{1} & \begin{array}{l}\text { A } \text { fit } \\ \text { C } \text { the requirements of }\end{array} \\ \mathbf{2} & \begin{array}{l}\text { A } \text { start } \\ \text { C } \text { begin }\end{array} \\ \mathbf{3} & \begin{array}{l}\text { A liking } \\ \text { C loving }\end{array} \\ \mathbf{4} & \begin{array}{l}\text { A grasp } \\ \mathbf{C} \text { scope }\end{array} \\ \mathbf{5} & \begin{array}{l}\text { A in } \\ \text { C } \text { of }\end{array} \\ \mathbf{6} & \begin{array}{l}\text { A phenomenal } \\ \mathbf{C} \text { magnificent }\end{array}\end{array}$

B meet
D suit
B commence
D mean
B telling
D saying
B range
D reach
B at
D on
B wondrous
D terrific

$7 \quad$ A the

C my

8 A next

C first

$9 \quad$ A drop

$10 \quad \mathbf{A}$ around

C aloud

11 A deny

C say

$12 \quad A$ and

C with

$13 \mathrm{~A}$ in

C on

14 A eyes

C hands

15 A this

C she

16 A people

C enemies

17 A however

C but

18 A when

C as

19 A people

C enemies

20 A is

C isn't

21 A shine

C love

22 A bikes

C cheeks

23 A the

C a
B a

D this

B a

D then

B go

D fall

B above

D about

B tell

D cry

B but

D or

B at

D of

B feet

D heart

B it

D that

B friends

D they

B while

D whenever

B if

D whenever

B friends

D they

B 's

D is not

B sun

D fun

B breasts

D horses

B that

D this 


\begin{tabular}{|c|c|c|c|}
\hline INSTRUCTIONS: Choose the most appropriate answer. You will have 20 & 1 & A dubbed & B called \\
\hline minutes. & 2 & $\begin{array}{l}\text { C named } \\
\text { A delight }\end{array}$ & $\begin{array}{l}\text { D denominated } \\
\text { B gratification }\end{array}$ \\
\hline Why the Yogic way for food? & & C pleasure & D happiness \\
\hline & 3 & $\mathbf{A}$ in & B at \\
\hline $\begin{array}{l}\text { Yoga is the only science that has placed great emphasis on food over } \\
\text { centuries. In fact, there is a whole branch }-\ldots \ldots \ldots \ldots 1 \ldots \ldots \ldots \text { Anna Yoga - } \\
\text { devoted to food for health and } \ldots \ldots 2 \ldots \ldots \ldots\end{array}$ & 4 & $\begin{array}{l}\text { C on } \\
\text { A philosophy } \\
\text { C philosophies }\end{array}$ & $\begin{array}{l}\text { D of } \\
\text { B possibility } \\
\text { D possibilities }\end{array}$ \\
\hline & 5 & $\begin{array}{l}\text { A techniques } \\
\text { C approaches }\end{array}$ & $\begin{array}{l}\text { B approaches } \\
\text { D ways }\end{array}$ \\
\hline $\begin{array}{l}\text { Over centuries, Yoga has developed a concept } \ldots \ldots 3 \ldots \ldots \text { a balanced whole- } \\
\text { food diet and an eating } \ldots \ldots . . \ldots \ldots \ldots \text { These principles of good eating use }\end{array}$ & 6 & $\begin{array}{l}\text { A healthier } \\
\text { C healthily }\end{array}$ & $\begin{array}{l}\text { B healthy } \\
\text { D health }\end{array}$ \\
\hline powerful ............... which help in maintaining a strong & 7 & A feeling & B atmosphere \\
\hline and ......6......body, a stress-free mind and a positive .....7.. & & C spirituality & D belief \\
\hline within this mixed-up world. & 8 & A that & B such \\
\hline & & C -- & D this \\
\hline & 9 & $\begin{array}{l}\text { A required } \\
\text { C needed }\end{array}$ & $\begin{array}{l}\text { B demanded } \\
\text { D desired }\end{array}$ \\
\hline $\begin{array}{l}\text { Never has } \ldots \ldots 8 \ldots \ldots \ldots \text { Yogic philosophy of a balanced whole-food diet } \\
\text { been } \ldots \ldots \ldots 9 \ldots \ldots \text { more than today when } 97 \% \text { of all } \ldots \ldots \ldots 10 \ldots \ldots \ldots\end{array}$ & 10 & $\begin{array}{l}\text { A healthier } \\
\text { C healthily }\end{array}$ & $\begin{array}{l}\text { B healthiest } \\
\text { D health }\end{array}$ \\
\hline disorders can be traced to a faulty $\ldots \ldots . .11 \ldots \ldots$ and diet. & 11 & $\begin{array}{l}\text { A nutrition } \\
\text { C nourishment }\end{array}$ & $\begin{array}{l}\text { B nutriment } \\
\text { D nutrient }\end{array}$ \\
\hline & 12 & $\begin{array}{l}\text { A Swedish } \\
\text { C Canadian }\end{array}$ & $\begin{array}{l}\text { B Indian } \\
\text { D Belgian }\end{array}$ \\
\hline It has been observed that (East) $\ldots \ldots . .12 \ldots \ldots \ldots$ civilizations suffer least & 13 & A indigestion & B headache \\
\hline from bowel problems, constipation, $\ldots \ldots \ldots 13 \ldots \ldots \ldots$ and other food related & & C fatigue & D backache \\
\hline disorders such as .......14 ........ Do you know why? Because the & 14 & A obesity & B fatness \\
\hline Indian $\ldots \ldots . .15 \ldots \ldots$ of cooking and eating draws heavily from $\ldots \ldots 16 \ldots \ldots$ & & C bigness & D heaviness \\
\hline yogic philosophy of eating! & 15 & A philosophy & B lifestyle \\
\hline & & C logic & D possibility \\
\hline & 16 & A -- & B this \\
\hline & & C the & D such \\
\hline Yoga does not .....17...... food into vitamins, minerals, protein & 17 & A provide & B analyze \\
\hline etc..The $\ldots . .18 \ldots \ldots$ philosophy is that the true benefits of & & C dissect & D synthesize \\
\hline these $\ldots \ldots .19 \ldots \ldots$ can be had only when they are $\ldots \ldots 20 \ldots \ldots$ isolated & 18 & A yoga & B yogi \\
\hline but are kept as much in their natural form as possible. & & C yogic & D -- \\
\hline & 19 & A components & B ingredients \\
\hline & & C elements & D constituents \\
\hline & 20 & A never & B not only \\
\hline & & C -- & D not \\
\hline The key to .....21..... health is to have a balanced whole- & 21 & A true & B real \\
\hline food $\ldots \ldots 22 \ldots \ldots \ldots$. A balanced diet ensures that all the $\ldots \ldots . .23 \ldots \ldots$ of & & C truly & D really \\
\hline digestion work smoothly-absorption, assimilation and & 22 & A style & B nourishment \\
\hline elimination. .......24 ........ balanced whole-food diet ensures a healthy & & C improvement & D diet \\
\hline you! & 23 & A aspects & B sections \\
\hline & & C faculties & D means \\
\hline & 24 & A the & B a \\
\hline & & C one & D -- \\
\hline
\end{tabular}

\section{REFERENCES}

[1] Amer, A. A. (2003). Teaching EFL/ESL literature. The Reading Matrix 3.2, 63-73.

[2] Bagherkazemi, M. \& Alemi, M. (2010). Literature in the ESL/EFL classroom: Consensus and controversy. Linguistic and Literary Broad Research and Innovation 1.1, 1-12.

[3] Berardo, S. A. (2006). The use of authentic materials in the teaching of reading. The Reading Matrix 6.2, 60-69.

[4] Bhuvaneswari, V., \& Jacob, R. (2011). Language acquisition through short stories for second language learners. Studies in Literature and Language 3.3, 156-158. DOI: 10.3968

[5] Brown, H. D. (2000). Teaching by principles: An interactive approach to language pedagogy (2nd ed.). London: Longman.

[6] Cain, K., Oakhill, J. V., Barnes, M. A., \& Bryant, P. E. (2001). Comprehension skill, inference-making ability, and their relation to knowledge. Memory \& Cognition 29.6, 850-859.

[7] Carter, R. (1997). Investigating English discourse: Language, literacy and literature. London and New York: Routledge.

[8] Collins, A., Brown, J. S., \& Larkin, K. M. (1977). Inference in text understanding. University of Illinois, Technical Report No. 40, 1-34.

[9] Davoudi, M. (2005). Inference generation skill and text comprehension. The Reading Matrix 4.1, 106-123.

[10] Duff, A., \& Maley, A. (2003). Literature (12th ed.). Oxford: Oxford University Press.

[11] Erkaya, O. R. (2005). Benefits of using short stories in the EFL context. Asian EFL Journal.1-13.

[12] Gajdusek, L. (1988). Toward wider use of literature in ESL: Why and how. TESOL Quarterly 22.2, 227-257.

[13] Gordon, J. A., \& Harding, P. (2007). Essential Reading for IELTS. Higher Education Press. http://www.topsage.com (accessed $26 / 1 / 2009)$

[14] Khatib, M., \& Nourzadeh, S. (2011). Some recommendations for integrating literature into EFL/ESL classrooms. International Journal of English Linguistics 1.2, 258-263. DOI: 10.5539 
[15] Khatib, M., Rezaei, S., \& Derakhshan, A. (2011). Literature in EFL/ESL classroom. Canadian Center of Science and Education 4.1, 201-208. http://www.ccsenet.org/elt (accessed 18/07/2012).

[16] Kispal, A. (2008). Effective Teaching of Inference Skills for Reading. National Foundation for Educational Research. Research Report DCSF-RR031.

[17] Kopitski, M. (2007). Exploring the teaching of inference skills (Unpublished Master's thesis). Hamline University, the USA.

[18] Lazar, G. (1994). Using literature at lower levels. ELT Journal 48.2, 115-124.

[19] Pennell, D. (2002). Explicit Instruction for Implicit Meaning: Strategies for Teaching Inferential Reading Comprehension. Considerations: Inferential Comprehension, T/TAC W\&M, 1-800-323-4489, 1-16.

[20] Phillips, L. M. (1989). Developing and validating assessments of inference ability in reading comprehension. Technical Report No. 452.

[21] Povey, J. F. (1967). Literature in TESL programs: The language and the culture. TESOL Quarterly 1.2, 40-46.

[22] Savvidou, C. (2004). An integrated approach to teaching literature in the EFL classroom. The Internet TESL Journal X. 12. http://www.iteslj.org (accessed 22/07/2012).

[23] Su, S. W. (2010). Motivating and justifiable: Teaching western literature to EFL students at a university of science and technology. The Electronic Journal for English as a Second Language 14.1.

[24] Thom, N. T. T. (2008). Using literary texts in language teaching. VNU Journal of Science, Foreign Language 24, $120-126$.

[25] Thornbury, S. (2005). Beyond the sentence: Introducing discourse analysis. Oxford: Macmillan.

[26] Yeh, Y., Mctigue, E. M., \& Joshi, R. M. (2012). Moving from explicit to implicit: A case study of improving inferential comprehension. Literacy Research and Instruction, 51.2, 125-142. DOI: 10.1080

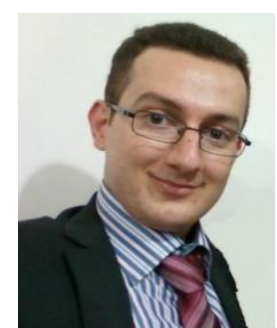

Reza Mokhtari is a Ph.D. candidate in TEFL at Azad University (Tabriz, Iran). He holds a B.A. in English Literature from Azad University (Alborz, Iran, 2008) and an M.A. in TEFL from Azad University, Science and Research Branch (Kermanshah, Iran, 2012). His main areas of interest include applied linguistics, discourse analysis and ESP. He has published and presented papers in these areas. 